\title{
Drill-Down Dashboard for Chairing of Online Master Programs in Engineering
}

\author{
Anabela Costa e Silva ${ }^{1(凶)}$ (D), Leonel Morgado ${ }^{2}$ (D) , and António Coelho ${ }^{3}$ \\ ${ }^{1}$ Faculty of Engineering of the University of Porto, Porto, Portugal \\ up201506034@fe.up.pt \\ 2 Universidade Aberta and INESC TEC, Coimbra, Portugal \\ Leonel. Morgado@uab.pt \\ 3 Faculdade de Engenharia, Universidade do Porto / INESC TEC, Porto, Portugal \\ acoelho@fe.up.pt
}

\begin{abstract}
Online masters' program chairs need up-to-date information to monitor efficiently and effectively all the courses in the program for which they are responsible.

Learning Management Systems supporting the operation of the online programme collect vast amounts of data about the learning process. These systems are geared to support individual teachers and students, not program chairs.

This article presents the process that led to the development of a Dashboards for program chairs, based upon an analysis of their regular supervision tasks, decision-making information needs, and available data in the learning management system, Moodle.

The information presented via the dashboard is aggregated and contextualised for all students enrolled in the program, in all its courses, contributing to improve decision-making in program chairing.

The dashboard prototype is presented as a concrete outcome of this process, which can be replicated to achieve more advanced and updated versions, hopefully contributing to better program chairing.
\end{abstract}

Keywords: Learning management systems · Dashboards · Program chairing · Program direction $\cdot$ Program coordination

\section{Introduction}

Recently, Learning Dashboards use and research surged significantly. Nevertheless, their application to support the role of masters' program chairs (also known as program directors or, in the non-English speaking world, program coordinators) has not been the focus of much analysis.

A program chair must ensure that students enrolled in the program have the support they need to be successful. They monitor the individual and collective learning process of the whole cohort to forecast student failure, and act to prevent it. The role of a program coordinator is also to cater for the resources and structure needed so that the program is successful. 
Most current tools aim to encourage the learning process, but focused on the role of students or teachers [10]. A program chair needs to consider several courses in parallel, not a single one. In the case of online programs, since educational activities take place in a Virtual Learning Environment (VLE) most commonly a structured one known as Learning Management System (LMS), there is plenty of data about occurrenes. However, this is mostly structured by individual or course, not by program. Similarly, data views and reports available in these VLE/LMS present information in suited for individual students and teachers, not chairs. From the viewpoint of program chairs, the information is scattered, lacking cohort context, course-comparison context, and hard to interpret.

This paper approached this problem by analysing the roles of program chairs in the context of Engineering Master Programs in Portugal, establishing available data in the context of online programs developed with the Moodle LMS, ascertaining the available data accessible via public Web services or log exports, and prototyping a sample dashboard to support some of the chairs' roles using those available data.

\section{Background: Dashboards for Masters Program Chairs}

A literature review of the use of dashboards by masters program chairs was conducted. The search was performed on the 14th of August 2020 and using Harzing's Publish or Perish software [3] to rank results from Google Scholar. We searched for "dashboard AND ("learning analytics" OR "educational data mining" OR "educational datamining") AND (master OR graduate) AND (administ* OR coordinat* OR advis* OR chair)", limiting the search for results from the year 2015 onward. This search string was used to compensate for different nomenclatures used for this position, like program chair or advisor. The first 19 results were selected. Two of these ([11] and [14]), were not peerreviewed works and were discarded, and one ([5]) was unavailable. In total 16 articles were read and analysed for this review.

Only two paper discussed in any way the role of masters program chairs. Strang [12] relates different approaches of employing Learning Analytics (LA) in Moodle, distinguishing between Course-level and Organizational-level information. Uskov et al. [13] provide a larger analysis of these various levels of depth, two of which are related to master program chairs: "Concentration/minor program level" and "Departmental/program of study/curriculum level". In their case, the master program chair has an analogous role to that of a department chair.

Overall, there was little specifically on program chairing support with dashboards. Possible reasons are that little has been written about existing dashboards for chairs, that there are few such dashboards, or that there is yet another nomenclature to describe them besides those we employed in this review.

\section{Problem Statement}

Moodle and other LMS have vast amounts of information about the education environment events. Nonetheless, they are geared towards supporting actions of individual teachers and students, and structure data and information by courses, dispersing the data and information required by program chairs for decision-making. Our aim was to create a 
dashboard-development process that can overcome this lack of information for program chairs. This process includes the analysis of program chairing tasks, of the decisionmaking associated with then, of the required information to support those decisions, of the available data towards those information in the LMS, and of the accessibility of those data from external systems.

\section{Methodology}

Design Science Research (DSR) seeks to learn from creating new and innovative artefacts and values learning by doing [4]. By applying DSR, researchers aim to create effective or useful artifacts, and learn from that creation process, generating knowledge from the adequacy analysis of the artifacts in concert with the principles employed in their design. Decision-support systems, such as dashboards, are a common artifact in DSR, as are modelling tools, governance strategies, or evaluation methods [2].

The fundamental questions for design-science research are, "What utility does the new artefact provide?" and "What demonstrates that utility?" [4].

We followed a DSR process with six activities or steps [6] to design and evaluate the dashboard prototype.

\section{Tasks Required of Master Program Chairs}

In Portugal, the functions of program chairs are specified in the statutes of each university. Their main function is, usually, to ensure the well-governance of the program. In the statutes of the University of Porto, the first duty of a program chair is to ensure the normal functioning of the program as well as to safeguard its quality [8]. However, the specific requirements and tasks vary between universities. Both the University of Porto's and the University of Trásos-Montes and Alto Douro's statutes specify that other tasks may be added $[1,9]$. At Universidade Aberta, its pedagogical model includes other functions in the role of program chairs [7].

To better understand and prioritize the task details of what master program chairs do, we interviewed 5 chairs. With the results of these interviews, 8 tasks were identified as having higher priority for chairs.

These tasks were spread unevenly throughout the academic year or semester. Task "Review and Rank Candidates' Applications" is done yearly at the beginning of the academic year; "Review the Courses' Reports" and "Register Dissertation Plans" are repeated at the beginning of each semester; "Oversee Absenteeism", "Prevent Dropout", and "Create and Review Student Results" are done regularly throughout the semester; "Review Satisfaction Surveys" is done at the end of each semester; and "Review Program Evaluation Reports" is done at an undefined by delimited time frame, dependent on data availability from academic services.

Do to their time dispersion and recurring nature, the tasks "Oversee Absenteeism", "Prevent Dropout", and "Create and Review Student Results", were selected for this dashboard prototype. The rationale was that the other tasks, due to their more restricted time frame, would be less critical, since chairs could devote a more focused effort for that short time span, rather than year-round. 


\section{Prototype}

Following the DSR process, iterative prototyping was done to design and develop the prototype. The final code is publicly available at https://github.com/AnabelaSilva/DIS SFEUP-20192020. Three iterations were made, the last one being analysed by 5 master program chairs, who were interviewed regarding the prototype relevance and adequacy.

The prototype dashboard contains three views: program-wide, student-wide, and course-wide.

\section{Mestrado em Tecnologias e Sistemas Informáticos Web - Dados fictícios}
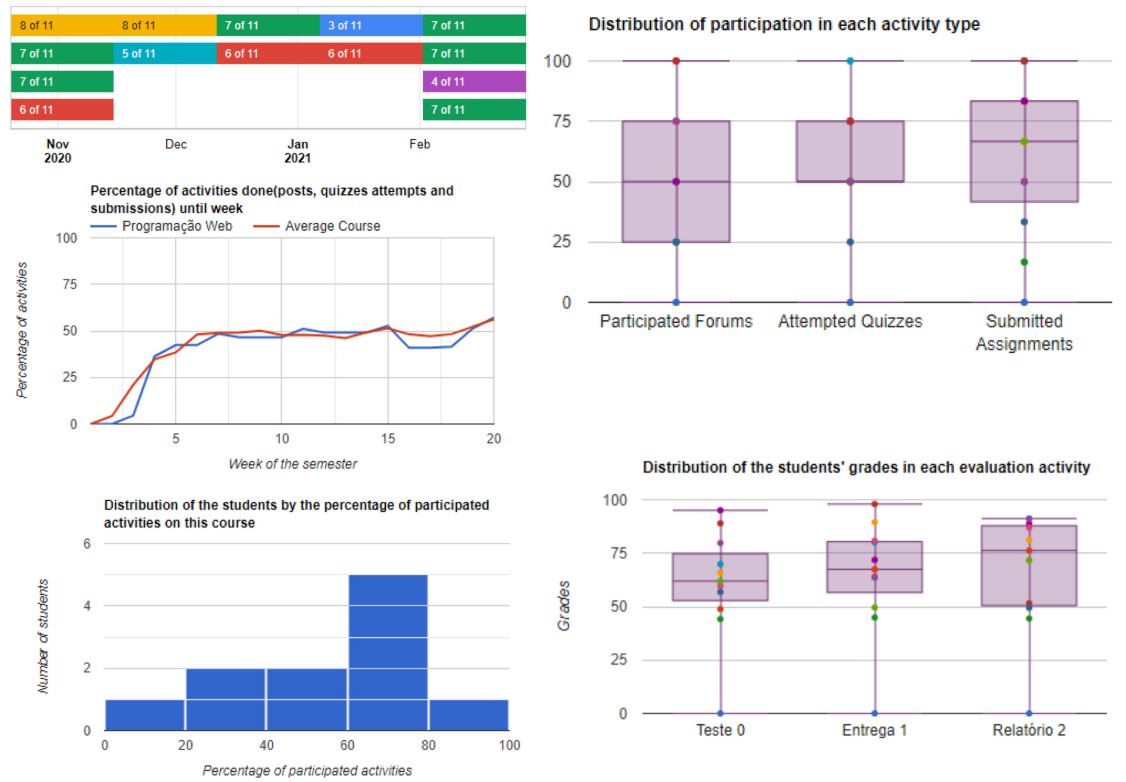

Fig. 1. Final prototype: screenshot of the course-wide view

The program-wide view is composed of four different displays that help the master program chair oversee the whole program: all students in all courses. Figure 3 depicts a screenshot of this view.

The student-wide view is composed of four different displays that allow the master program chair to see how a particular student is behaving in the program, in all courses, Fig. 2 depicts a screenshot of this view.

The course-wide view is composed of five different displays that allow the master program chair to see how a particular course is developing, with all students, in the context of the other courses. Figure 1 depicts a screenshot of this view. 


\section{Mestrado em Tecnologias e Sistemas Informáticos Web - Dados fictícios}

Student: Samara Bensaúde Pedro
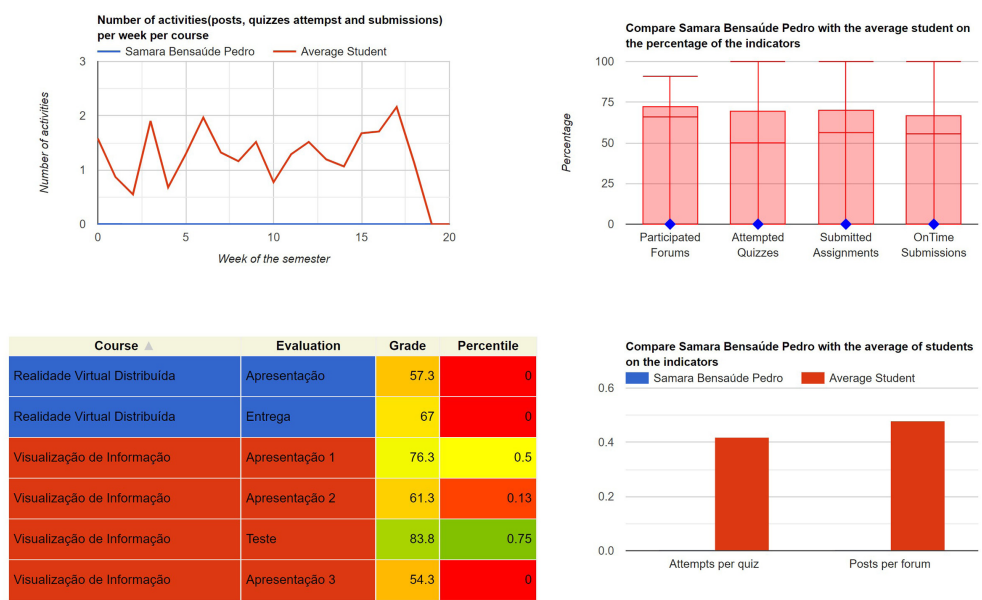

Fig. 2. Final prototype: screenshot of the student-wide view

\section{$\underline{\text { Mestrado em Tecnologias e Sistemas Informáticos Web - Dados fictícios }}$}
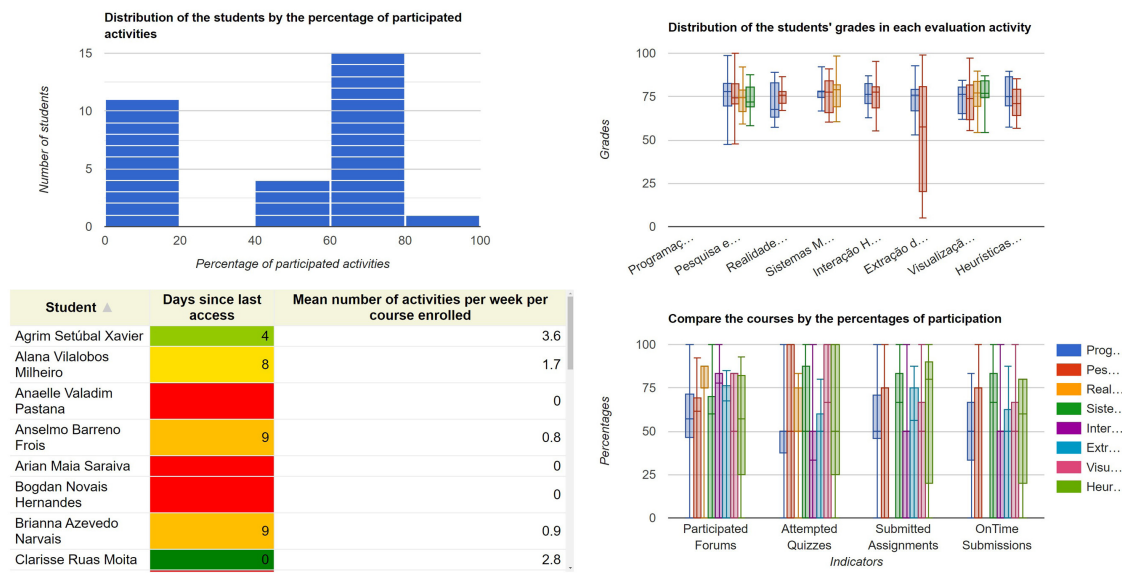

Fig. 3. Final prototype: screenshot of the program-wide view

\section{Conclusions and Future Work}

Herein we presented the process by which a dashboard was developed to support online master program chairing, resulting from the work developed for a master dissertation by the first author and her supervisors. The identification of the role and tasks of masters program chairs is a fist process step. Although the nomenclature and required tasks vary between institutions, some tasks are common to many chairing positions and can be useful for a wider audience. To conduct this first step, we used a literature review and 
interviews with 5 program chairs from 3 different universities. Future work should seek to establish a larger set of common chairing tasks, and compare distinct requirements across institutions, towards ascertaining which aspects are more generic in application and which are local.

From the outcome of this first step, three tasks were selected to be the focus of this work: "Oversee Absenteeism", "Prevent Dropout", and "Create and Review Student Results"). The remaining tasks are potential opportunities for future research on development of dashboards in support of program chairs decision making.

The combination of the interviews data with the literature review enabled the identification of three distinct view for decision-making, and of particular instruments and aspects for those views, represented in detail in the figures included in this paper. Preliminary validation of these instruments is promising, but more extensive analysis and evaluation is recommended to ascertain their impact on actual quality and effectiveness of decision-making by program chairs.

Acknowledgements. This work is co-financed by the ERDF - European Regional Development Fund through the Operational Programme for Competitiveness and Internationalization COMPETE 2020 and the Lisboa 2020 under the PORTUGAL 2020 Partnership Agreement, and through the Portuguese National Innovation Agency (ANI) as a part of project CHIC POCI-01-0247-FEDER-024498.

\section{References}

1. de Trás-os-Montes e Alto Douro, U.: Regulamento no 570/2018. Diário da República no. 161/2018, Série II de 2018-08-22. Accessed 5 Dec 2019

2. Gregor, S., Hevner, A.R.: Positioning and presenting design science research for maximum impact. Manag. Inf. Syst. Q. 37(2), 337-355 (2013). https://doi.org/10.25300/MISQ/2013/ 37.2.01

3. Harzing, A.: Publish or Perish (2007). https://harzing.com/resources/publish-or-perish. Accessed 29 July 2020

4. Hevner, A.R., March, S.T., Park, J., Ram, S.: Design science in information systems research. Manag. Inf. Syst. Q. 28(1), 75-105 (2004)

5. Jo, I.-H., Yu, T., Lee, H., Kim, Y.: Relations between student online learning behavior and academic achievement in higher education: a learning analytics approach. In: Chen, G., Kumar, V., Kinshuk, Huang, R., Kong, S.C. (eds.) Emerging Issues in Smart Learning. LNET, pp. 275-287. Springer, Heidelberg (2015). https://doi.org/10.1007/978-3-662-44188-6_38

6. Peffers, K., et al.: The design science research process: a model for producing and presenting information systems research. In: Proceedings of First International Conference on Design Science Research in Information Systems and Technology DESRIST, Claremont, California, USA, pp. 83-106 (2006)

7. Pereira, A., Mendes, A.Q., Morgado, L., Amante, L., Bidarra, J.: Modelopedagógico virtual da Universidade Aberta: para uma universidade do futuro. Universidade Aberta, Lisboa, Portugal, ISBN 978-972-674-493-1 (2007). https://hdl.handle.net/10400.2/1295

8. do Porto Reitoria, U.: Regulamento n. ${ }^{\circ}$ 699/2018. Diário da República n. ${ }^{\circ}$ 203/2018, Série II de 2018-10-22. Accessed 25 Jan 2020

9. do Porto Reitoria, U.: Regulamento n. ${ }^{\circ}$ 706/2018. Dia'rio da República n. ${ }^{\circ}$ 204/2018, Série II de 2018-10-23. Accessed 05 Dec 2019 
10. Schwendimann, B.A., et al.: Perceiving learning at a glance: a systematic literature review of learning dashboard research. IEEE Trans. Learn. Technol. 10(1), 30-41 (2015). https://doi. org/10.1109/TLT.2016.2599522

11. Sclater, N.: Learning Analytics Explained. Taylor \& Francis, New York (2017).ISBN 9781317394563

12. Strang, K.D.: Do the critical success factors from learning analytics predictstudent outcomes? J. Educ. Technol. Syst. 44(3), 273-299 (2016). https://doi.org/10.1177/0047239515615850

13. Uskov, V., et al.: Building smart learning analytics system for smart university. In: Uskov, V.L., Howlett, R.J., Jain, L.C. (eds.) SEEL 2017. SIST, vol. 75, pp. 191-204. Springer, Cham (2018). https://doi.org/10.1007/978-3-319-59451-4_19

14. West, D., et al.: Learning analytics: assisting universities with student retention, Case studies. Technical report, Australian Government Office for Learning and Teaching (2015). Project outcome of Final Report 